\title{
Mechanical Properties of Advanced Gas-Cooled Reactor Stainless Steel Cladding After Irradiation
}

\author{
Claude Degueldre, James Fahy, Oleg Kolosov, Richard J. Wilbraham, Max Döbeli, Nathalie Renevier, Jonathan Ball, and Stefan Ritter
}

(Submitted December 12, 2017; in revised form February 11, 2018; published online April 9, 2018)

\begin{abstract}
The production of helium bubbles in advanced gas-cooled reactor (AGR) cladding could represent a significant hazard for both the mechanical stability and long-term storage of such materials. However, the high radioactivity of AGR cladding after operation presents a significant barrier to the scientific study of the mechanical properties of helium incorporation, said cladding typically being analyzed in industrial hot cells. An alternative non-active approach is to implant $\mathrm{He}^{2+}$ into unused AGR cladding material via an accelerator. Here, a feasibility study of such a process, using sequential implantations of helium in AGR cladding steel with decreasing energy is carried out to mimic the buildup of He (e.g., 50 appm) that would occur for in-reactor AGR clad in layers of the order of $10 \mu \mathrm{m}$ in depth, is described. The implanted sample is subsequently analyzed by scanning electron microscopy, nanoindentation, atomic force and ultrasonic force microscopies. As expected, the irradiated zones were affected by implantation damage $(<1 \mathrm{dpa})$. Nonetheless, such zones undergo only nanoscopic swelling and a small hardness increase $(\sim 10 \%)$, with no appreciable decrease in fracture strength. Thus, for this fluence and applied conditions, the integrity of the steel cladding is retained despite $\mathrm{He}^{2+}$ implantation.
\end{abstract}

Keywords atomic force microscopy, hardness, helium implantation, nanoindentation, stainless steel

\section{Introduction}

Since the start of the 1970 s, the UK has operated a fleet of nuclear reactors quite different to the light-water moderated reactors (LWR) typically found across the rest of the world. The advanced gas-cooled reactor (AGR) uses a graphite core and $\mathrm{CO}_{2}$ cooling with an annular in shape, slightly enriched (up to $3.5 \% \mathrm{U}^{235}$ ) uranium dioxide-based fuel clad in stainless steel rather than Zircalloy.

This cladding is rich in both nickel $(\sim 25$ wt.\%) and chromium $(\sim 20$ wt. $\%)$ in order to withstand high gas temperatures (Ref 1). However, during in-reactor irradiation helium gas bubbles are generated by three different interaction routes with common elements within the steel. First, via neutron irradiation, nickel isotopes may undergo neutron capture. Among them, ${ }^{58} \mathrm{Ni}(68 \%$ abundance in natural nickel) reacts with a neutron producing ${ }^{59} \mathrm{Ni}$ that after a second neutron capture yields an alpha particle which becomes helium.

Claude Degueldre and Richard J. Wilbraham, Engineering Department, Lancaster University, Lancaster LA1 4YW, UK; James Fahy, Engineering Department, Lancaster University, Lancaster LA1 4YW, UK; and Jost Institute, University of Central Lancashire, Preston PR1 2HE, UK; Oleg Kolosov, Physics Department, Lancaster University, Lancaster LA1 4BA, UK; Max Döbeli, Laboratory of Ion Beam Physics, ETH Zurich, 8093 Zurich, Switzerland; Nathalie Renevier, Jost Institute, University of Central Lancashire, Preston PR1 2HE, UK; Jonathan Ball, EDF-Energy, Fuel Group CTO, Barnwood, Gloucester GL4 3RS, UK; and Stefan Ritter, Laboratory of Nuclear Materials, Paul Scherrer Institute, 5232 Villigen, Switzerland. Contact e-mail: c.degueldre@lancaster.ac.uk.
For thermal neutrons, the cross sections of the first and second reaction are, respectively, 4 and 12 barns. Initially, Greenwood et al. (Ref 2) compared the measured and calculated helium production in nickel using new evaluated cross sections for ${ }^{59} \mathrm{Ni}$. Later, Gopalakrishnan et al. (Ref 3) compared the calculated helium production obtained by neutron irradiation in stainless steel with that found experimentally.

Secondly, thermal neutrons may react with ${ }^{10} \mathrm{~B}$, producing He density that can be quantified using the neutron absorption relationship buildup with time.

For the reactor flux and the irradiation time, the contribution reaction is then given by the ratio of the density, flux and cross section of the absorbing nuclide. For the case of an nuclear steel, the impact of bore is negligible.

Finally, fast neutrons may also react with transition metal isotopes. However, within the AGR reactor, their flux is smaller than the thermal neutron flux. Furthermore, the cross section of fast neutron $M(n, \alpha)$ reactions is also smaller making this production path slower than $\mathrm{He}$ production by thermal neutrons.

The so generated helium segregates at grain boundaries and can act as nucleation sites for embrittlement (Ref 4, 5). Such embrittlement results in a reduction in the energy to fracture, due to a reduction in strain hardening (as hardening is already occurring during irradiation). This is motivated by very similar reasons to those that cause radiation hardening, i.e., development of defect clusters, dislocations, voids and precipitates. Variations in these parameters make the exact amount of embrittlement difficult to predict, but the generalized values for the measurement show predictable consistency (Ref 6).

Historically, mechanical testing via microscopy and simple hardness testing has been found to be a suitable way of determining the effects of helium-initiated embrittlement and how (if at all) the integrity of AGR clad is compromised. Early studies by Madden and Callen (Ref 7) used electron microscopy to investigate the microstructure of neutron irradiated $20 \mathrm{Cr} / 25 \mathrm{Ni} / \mathrm{TiN}$ austenitic stainless steel after irradiation at 
$783 \mathrm{~K}$ to a neutron fluence of $5.0 \times 10^{24} \mathrm{~m}^{-2}$ (thermal) and $2.5 \times 10^{24} \mathrm{~m}^{-2}$ (fast). The austenitic matrix was free of irradiation-induced damage, while the TiN particles contained nanoloops which coarsened into a network upon annealing at $1083 \mathrm{~K}$. Annealing also resulted in a low density of transmutation-induced helium bubbles, $\sim 4 \mathrm{~nm}$ in diameter, located in precipitate-free regions of grain boundaries. The material was found to be relatively unaffected by irradiation at these fluence levels, and helium bubble embrittlement was unlikely under normal stresses.

Following on from this, Odette and Lucas (Ref 8) tested the effects of intermediate temperature irradiation on the mechanical behavior of several austenitic stainless steels. They described how visible irradiation-induced features are predominantly helium bubbles and dislocation loops. Further, the uniform elongation is reduced to less than $1 \%$ due to the decrease in strain hardening and severe flow localization following irradiation.

Since 1991 several other steel types have been tested by various authors. Hashimoto et al. (Ref 9) studied mixedspectrum irradiation on ferritic/martensitic steels, as well as investigating the pros and cons of nickel and boron doping to produce helium embrittlement.

Review on the analysis of helium effects has been reported by Klueh et al. (Ref 10). The same year, Yamamoto et al. (Ref 11) reported on the effects of irradiation and helium on the yield stress changes and hardening and non-hardening embrittlement of martensitic steels.

Pouchon et al. (Ref 12) used x-ray absorption spectroscopy to study irradiated oxide dispersion strengthened steels. Finally, Cammelli et al. (Ref 13) investigated a neutron irradiated reactor pressure vessel steel by x-ray absorption spectroscopy.

However, since these studies, characterization studies on stainless steel after irradiation have been reported by Degueldre et al. (Ref 14) using advanced analytical techniques such as $\mathrm{X}$-ray absorption spectroscopy.

More recently, Dai et al. (Ref 15) report on the He effects on the microstructure and mechanical properties of ferritic/martensitic steels and this year, Villacampa et al. (Ref 16) complete the work following the helium bubble evolution by post-implantation annealing and the hardening in $316 \mathrm{~L}$.

A major hurdle in the further study of irradiation damaged clad is that in-reactor or external neutron irradiation results in the generation of many high activity isotopes within the steel, making conventional laboratory analysis prohibitive unless carried out within an industrial hot cell. An alternative approach developed within the last 10 years is to implant $\mathrm{He}^{2+}$ into unused steel using an accelerator. The result is a sample that mimics the irradiation-induced generation of $\mathrm{He}$ but is nonactive and therefore easy to investigate within a conventional laboratory. Such a technique has been used by Jublot-Leclerc et al. (Ref 17), who performed TEM studies on the nucleation of bubbles induced by He implantation in industrial austenitic stainless steel, and Liu et al. (Ref 18), who carried out TEM studies of nanostructured reduced activation ferritic/martensitic (RAFM) steel irradiated with He ions.

Here, a feasibility study using a similar method of He ion implantation, but using sequential implantations rather than a single irradiation of $\mathrm{He}^{2+}$ with decreasing energy to mimic the buildup of $\mathrm{He}$ (e.g., 50 appm) that would occur for in-reactor AGR clad, is described. The required He fluency $\left(\mathrm{cm}^{-2}\right)$ has been estimated for the implantation time and is comparable to that reached in-pile during reactor operation. In addition, more advanced imaging/hardness testing techniques have been applied to these samples, specifically nanoindentation, but also scanning electron microscopy (SEM), atomic force microscopy (AFM) and ultrasonic force microscopy (UFM), in order to carry out a microstructural study of the mechanical property evolution during helium irradiation and post-irradiation annealing of AGR clad.

Nanoindentation is a mature technique for measuring the mechanical properties of materials on a nanoscale. However, its application to hardness measurements of ion-irradiated materials has only recently emerged, initially through applicability tests by Hosemann et al. (Ref 19) and further refined using the models of Liu et al. (Ref 20). The models of Liu et al. showed that while the measured nanoindentation hardness needs to be converted to the bulk-equivalent hardness by using computation models, the fitting results obtained reveal that the modified model describes very well the hardness data obtained from different ion-irradiation systems such as helium and hydrogen. Their proposed model not only revealed the hardness of the irradiated-hardening layer and substrate, but also allowed quantitative understanding on the indentation size effect. Indeed, earlier last year, Ding et al. (Ref 21) successfully measured the hardening of oxide dispersion strengthened ferritic steels under irradiation with high-energy heavy ions using nanoindentation.

As this is a feasibility study, future post-implantation treatments are also foreseen to explore the healing effect of temperature on the irradiation damaged material as well as on the release of helium. Post-treatment analysis is also required to observe the effect of temperature and treatment duration on the size distribution of He bubbles, with the expected final result to fix recommendations on the impact of nickel and treatment on the integrity of the nuclear material with emphasis on the AGR reactor, but also with possible applications to LWR/PWR vessels or accident tolerant stainless steel cladding.

\section{Experimental}

\subsection{Material}

The AGR stainless steel cladding is austenitic in nature. Its "as delivered" composition is $20 \mathrm{Cr} / 25 \mathrm{Ni} / 0.7 \mathrm{Mn} / 0.5 \mathrm{Nb}$, with $\mathrm{Nb}$ present in precipitates.

The steel tubes are first cold rolled so that their initial thickness of $1.6 \mathrm{~mm}$ is reduced to $0.8 \mathrm{~mm}$. The material is subsequently heated up to $970{ }^{\circ} \mathrm{C}$ for $30 \mathrm{~min}$ under an atmosphere of $\mathrm{Ar}$ and $\mathrm{H}_{2}(\sim 1 \%)$. The grain size is typically $10 \mu \mathrm{m}$. As stated earlier, AGR clad contains a significant proportion of $\mathrm{Nb}(0.5$ wt. $\%)$. The added niobium reacts with the carbon dissolved in the steel to produce $\mathrm{NbCN}$ nanoparticles that can be found with $\mathrm{FeC}$ nanophases in grain boundaries. These $\mathrm{NbCN}$ nanoparticles pin the grain, stopping secondary recrystallization and reducing the ductility of the material (Ref 22). Thus, its structure is ODS like, with the dispersion of niobium carbide nanoparticles used to stabilize the steel.

Upon delivery, the sample was further prepared by systematic polishing with P2500 (8.4 $\pm 0.5 \mu \mathrm{m}$ grain size) and P4000 $(6.5 \pm 0.5 \mu \mathrm{m}$ grain size) $\mathrm{SiC}$ paper for $2-3 \mathrm{~min}$ each, followed by successive lapping with diamond polishing pastes of successively decreasing grades of $9,6,3$ and $1 \mu \mathrm{m}$, respectively, for $1.5 \mathrm{~min}$ each. 
The final $7 \mathrm{~mm} \times 4 \mathrm{~mm}$ sample was mounted on the accelerator sample carrier using 2 screws. A 400-mesh (37.5 $\mu \mathrm{m}$ aperture), G400P-N3 type TEM copper grid was added to the surface of the steel samples to produce a regular pattern of irradiated and unirradiated surface regions. This TEM grid was adhered to the planed sample surface using a microdrop of Plano carbon (N650, Planocarbon, Groepl, Austria).

\subsection{Implantation}

He implantation was carried out at the ETH Zurich $6 \mathrm{MV}$ tandem accelerator. All implantation steps were performed at an initial He energy of $5 \mathrm{MeV}$. To obtain a more uniform He depth distribution in the top $10 \mu \mathrm{m}$ of the sample surface, aluminum degrader foils of 5, 10, 15 and $20 \mu \mathrm{m}$ were sequentially used. The He beam was focused to a spot of about $1 \mathrm{~mm}$ diameter at a current of $(150 \pm 10) \mathrm{nA}$ and raster scanned across an area of $6 \mathrm{~mm} \times 6 \mathrm{~mm}$.

\subsection{Nanoindentation}

In order to perform a measurement, the indentation head was placed onto the sample surface using an optical microscopy unit. Indentation force was then increased to the maximum and subsequently released. The head was then displaced above the sample to the next point in the vicinity for a new mechanical cycle and repeated sequentially to cover the required sample area, with the indentation force and displacement recorded for data analysis.

Nanoindentation tests were carried out using a Micro Material unit Platform 3. The instruments original design was developed by Newey et al. (Ref 23) by Lancaster University and Micro Materials (formed in 1988 by Dr Jim Smith), which first began selling such instruments in 1992. The Platform 3 uses a diamond indenter of a Berkovich type, a three-faced pyramidal having the same depth to area ratio as a Vickers indenter. The Berkovich tip has a very flat profile, with a total included angle of $142.3^{\circ}$ and a half angle of $65.27^{\circ}$, measured from the axis to one of the pyramid flats. As it is three sided, it is easier to grind these tips to a sharp point and so is more readily employed for nanoindentation tests. Such a tip is typically used to measure bulk materials and films greater than $100 \mathrm{~nm}$ thick (Ref 24).

As discussed by Sakharova et al. (Ref 25), depth-sensing indentation measurements are used to determine the hardness and the Young's modulus. The hardness, $H_{\mathrm{IT}}$, is evaluated by (e.g., Ref 26) using:

$H_{\mathrm{IT}}=\frac{L_{\mathrm{Max}}}{A}$

where $L_{\mathrm{Max}}$ is the maximum applied load and $A$ is the residual indentation area, at the maximum load.

The area function of the Berkovich indenters is given by:

$A=24.675 h^{2}+0.562 h+0.003216$

with $A\left(\mu \mathrm{m}^{2}\right)$. The ideal indentation depth for the area $A$ is then given by:

$A=/ 24.5 h^{2}$

This method is based on the acquisition of force curves that are analyzed instantaneously.

The accuracy of the hardness results, obtained with Eq 1-3, depends on the evaluation of contact area and compliance. In this study, the contact area, $A$, was evaluated using the contour of the indentation (see section 3 ). Using this approach, contact area results are independent of the formation of pileup and sinkin. Indentation was performed stepwise from 0.5 to $1.0 \mu \mathrm{m}$ in depth in a He-implanted layer from the surface to a maximum of about $10 \mu \mathrm{m}$ in depth.

\subsection{Scanning Electron, Atom Force and UItrasonic Force Microscopies}

Scanning electron microscopy examinations were performed at $20 \mathrm{kV}$ using a JEOL 6010-LV (JEOL (UK) Ltd., Herts, UK).

For the nanoscale characterization of samples and the formed nanoindentations, a Multimode Atomic Force Microscope (AFM) with Nanoscope 8 controller (Bruker, USA) was used. Surfaces were imaged in contact mode using a contact $\mathrm{Si}$ cantilever with $10 \mathrm{~nm}$ radius of curvature (ContAl-G, Budget Sensors, Germany) producing topographical images with lateral resolution of better than $5 \mathrm{~nm}$ and dimensional accuracy of $3 \times 10^{-2}$

The ultrasonic force microscope (UFM) deploys a highfrequency ultrasonic vibration that is nonlinearly detected by an AFM tip to map local mechanical moduli of materials with the same similar nanometer scale lateral resolution as traditional atomic force microscopy (Ref 27). This near field combination acoustic microscopy image (Ref 28, 29) also has the benefits of nanoscale spatial resolution (Ref 27 ) and significantly reduced friction (30) that minimizes damage both to the sample and the tip ensuring consistent measurement results. As such, it allows investigation in a nondestructive way of specific features such as defects, cracks delamination and, in particular, voids such as helium bubbles.

\section{Results}

\subsection{Implantation}

Implantation was performed in five steps with an initial He energy of $5 \mathrm{MeV}$, and the four degrader foils are described in section 2.2 with a total ion fluence of $5 \times 10^{15} \mathrm{~cm}^{-2}$ to produce an average He bulk density in the top $10 \mu \mathrm{m}$ of the sample of approximately $5 \times 10^{18} \mathrm{~cm}^{-3}$, simulating a cladding after reactor operation.

The irradiation sequence has been estimated as the optimum beam-time utilization. In addition, energies higher than $5 \mathrm{MeV}$ are not considered because they might lead to implantationinduced activation. Simulations were carried out using the irradiation simulation software SRIM (Ref 31), which is based on a Monte Carlo simulation using the binary collision approximation with a random selection of the impact parameter of the next colliding ion. As input parameters, it needs the ion type (isotope from ${ }^{1} \mathrm{H}$ to ${ }^{238} \mathrm{U}$ ) and its energy (in the range of $10 \mathrm{eV}-2 \mathrm{GeV}$ ) and the material of one or several target layers (see Ref 32, 33). From these simulations, the irradiation profile shown in Fig. 1 is obtained. The average penetration depths for the five implantation steps are given in Table 1 along with other implantation characteristics. The SRIM results show that $\mathrm{He}^{2+}$ penetration ranges from 9.5 to $1.5 \mu \mathrm{m}$ as the thickness of the $\mathrm{Al}$ foil increases. However, the real distribution of each peak must be broader due to roughness of the degrader foils. The damage calculations show that the He peaks reach 0.05 dpa. 


\subsection{Scanning Electron Microscope Imaging}

SEM micrographs for both the TEM grid obscured regions of the He-implanted steel (A and B) and the 400 mesh Cu TEM grid itself (C and D) are shown in Fig. 2.

Examination of the images in Fig. 2(a) and (b) reveals a square array of implanted zones is created on the steel after $\mathrm{He}$ implantation and subsequent removal of the TEM grid. The implanted square zones appear in a darker gray than the nonimplanted zones formed by the grid shadow. Such changes in contrast likely correspond to a flat smooth metallic surface for the non-implanted zones, due to shielding of the steel by the TEM grid and rough swelled surfaces, appearing darker as a result of enhanced electron scattering, in implanted areas.

In order to determine a suitable spatial pattern for nanoidentation, measurements were also taken for five individual squares of the TEM grid, Fig. 2(c), and implanted zones of the steel, Fig. 2(b), with an example of the measured dimensions shown in Fig. 2(d). The results of this analysis are shown in Table 2.

Table 2 reveals that the grid and square sizes are $33 \pm 3 \mu \mathrm{m}$, with a spacing between squares of $27 \pm 2 \mu \mathrm{m}$. As the indentation array size is $40 \times 40 \mu \mathrm{m}$, tests in section 3.3 (below) are performed across both the irradiated and nonirradiated parts of the He-implanted steel.

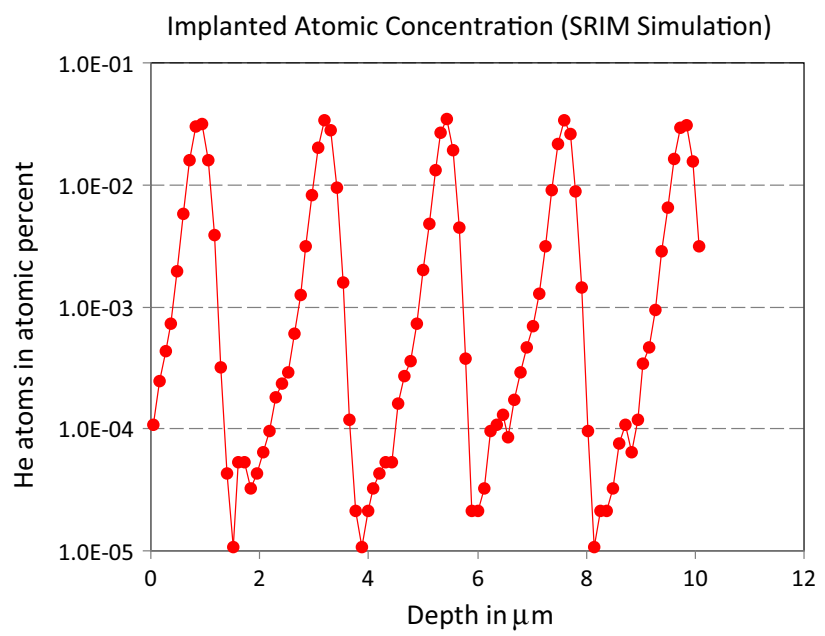

Fig. 1 SRIM calculated implantation profiles of $5 \mathrm{MeV} \mathrm{He}^{2+}$ in the AGR cladding steel without and with energy reduction via the aluminum absorbers. The Fe atom density is $9 \times 10^{22} \mathrm{~cm}^{-3}$, and the He fluence is $1 \times 10^{15} \mathrm{~cm}^{-2}$ for each implantation step

\subsection{Nanoindentation}

Indentation was performed along 10 rows and 10 columns $(10 \times 10$ array $)$ with an indentation spacing of 30 microns. With the TEM grid of $37 \mu \mathrm{m}$, indentations are performed on the grid shadow and on the irradiated squares shown in the previous section. Load varied between 10 and $20 \mathrm{mN}$ with increments of $0.1 \mathrm{mN}$. Traces of the indents can be measured. The loading and unloading versus penetration depth curves are shown in Fig. 3.

The loading parts of Fig. 3 do not reveal discontinuities that would be typically recorded during either crack or fissure formation. The penetration goes from $600 \mathrm{~nm}$ at minimum loading to $1100 \mathrm{~nm}$ at the highest loading. Zero load correction and thermal drift corrections were made. In the unloading program, discontinuities around $2 \mathrm{mN}$ are recorded for all maximum loads. These discontinuities are an indication of the occurrence of a structural phase transition and could be eliminated with lower loading. From Fig. 3, it can also be observed that at loads less than $19 \mathrm{mN}$ the material has a viscoelastic behavior and potential for energy storage. However, the results across areas do not show any fundamental differences. At loadings above $19 \mathrm{mN}$, short plateaus are found at high penetration depth and the unloading curves show a slight change in stiffness, a sign that there could be some minor creep behavior occurring.

The plastic hardness as a function of load at the 100 indentation sites is shown in Fig. 4.

From Fig. 4, it can be seen that, as expected, as the load increases the hardness decreases. Theoretically, it would be expected that irradiation should change the hardness behavior of the stainless steel, i.e., increases in the hardness with intercalation of He into the structure should be observed. As sampling is carried out across both irradiated and non-irradiated areas (due to the TEM grid pattern, Fig. 2b), high values surrounded by lower values in a repetitive manner would confirm that there is a variation in hardness with irradiation as indentations pass repeatedly from irradiated to non-irradiated area across the grid pattern.

Thus, from Fig. 4, it appears that the implanted areas are, as expected, slightly harder than the non-implanted one. This has been further highlighted in Fig. 4 by the plotting of fitting curves through points at the maximum and minimum of deviation from the normal load curve. The upper curve series is due to the larger load required for given penetration in the implanted areas, with the lower curve representative of measurements taken at non-implanted areas. Therefore, via comparison between the two curves, Fig. 4 also shows that the difference in hardness between irradiated and non-irradiated regions is on the order of $\sim 10 \%$. It is also important to note that the depth investigated here ranged from 500 to $1000 \mathrm{~nm}$,

Table 1 Evaluation of Al foil absorber effect on the implantation data for $5 \mathrm{MeV} \mathrm{He}^{2+}$ in the AGR stainless steel sample

\begin{tabular}{|c|c|c|c|c|}
\hline $\begin{array}{l}\text { Al absorber } \\
\text { thickness, } \mu \mathrm{m}\end{array}$ & $\begin{array}{l}\mathrm{He}^{2+} \text { energy at steel } \\
\text { surface, } \mathrm{MeV}\end{array}$ & $\begin{array}{l}\text { Penetration depth and its } \\
\text { standard deviation, } \mu \mathrm{m}\end{array}$ & $\begin{array}{l}\text { Implantation } \\
\text { time, min }\end{array}$ & $\begin{array}{c}\text { Average } \mathbf{H e}^{2+} \\
\text { current, } \mathbf{n A}\end{array}$ \\
\hline 00 & 5.00 & $9.5 \pm 0.5$ & 14 & 150 \\
\hline 05 & 4.14 & $7.5 \pm 0.4$ & 12 & 160 \\
\hline 10 & 3.17 & $5.5 \pm 0.6$ & 12 & 155 \\
\hline 15 & 1.99 & $3.5 \pm 0.4$ & 12 & 155 \\
\hline 20 & 0.41 & $1.5 \pm 0.2$ & 12 & 160 \\
\hline
\end{tabular}



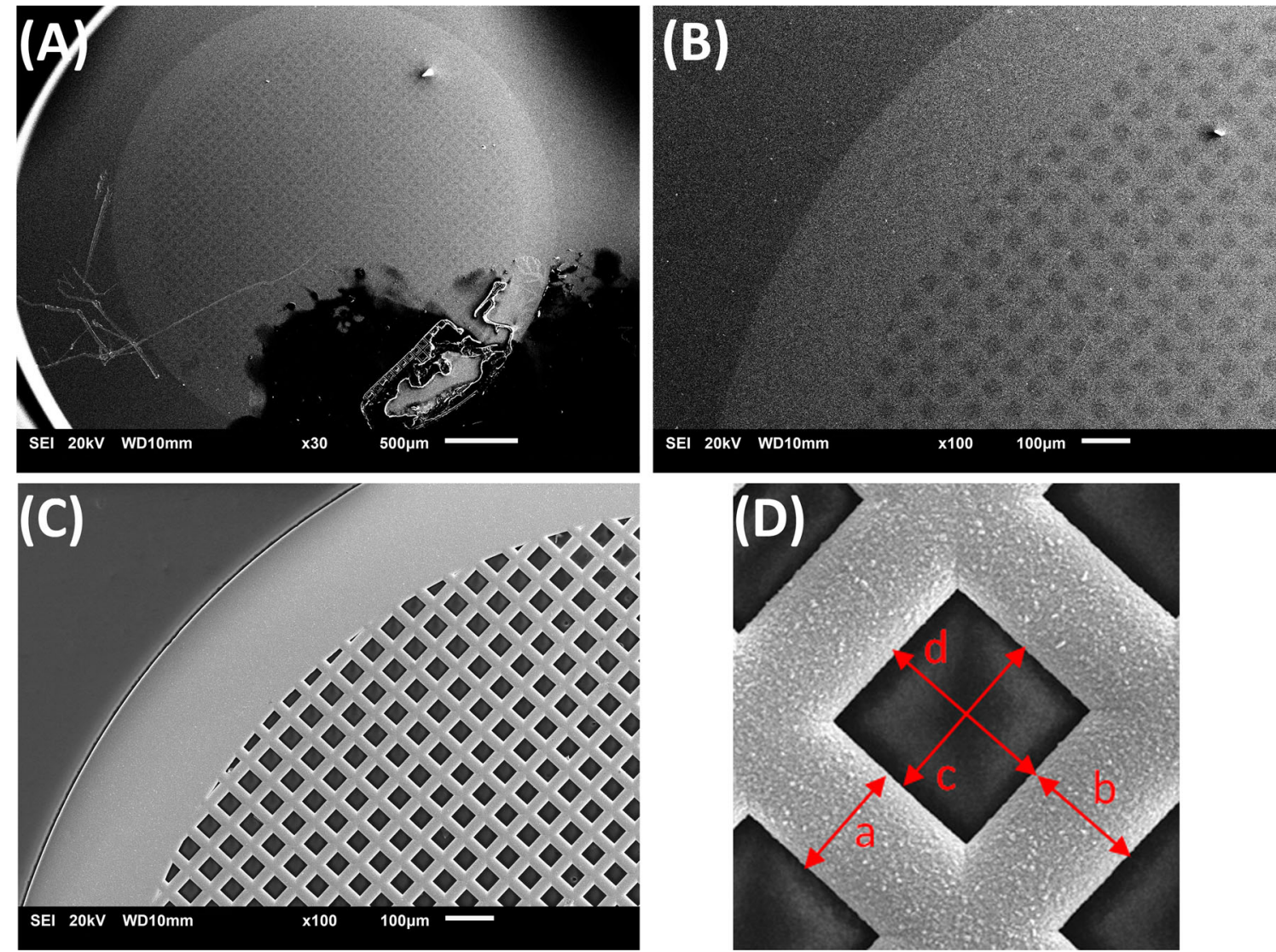

Fig. 2 SEM secondary electron images of (a) $30 \times$ magnification of the TEM grid obscured region of the He-implanted steel, (b) $100 \times$ magnification of the obscured region of the He-implanted steel, (c) 100× magnification of a 400 Mesh copper TEM grid and (d) labeled dimensions of a single TEM grid square

Table 2 Measured dimensions of a 400-mesh TEM grid and the TEM obscured region of the He-implanted steel

\begin{tabular}{lcccc}
\hline & $\boldsymbol{a}, \boldsymbol{\mu m}$ & $\boldsymbol{b}, \boldsymbol{\mu m}$ & $\boldsymbol{c}, \boldsymbol{\mu m}$ & $\boldsymbol{d}, \boldsymbol{\mu m}$ \\
\hline TEM grid & $25.5 \pm 0.3$ & $25.1 \pm 0.9$ & $36.9 \pm 0.6$ & $36.5 \pm 0.4$ \\
Implanted steel & $28.1 \pm 2.6$ & $29.3 \pm 2.6$ & $32.1 \pm 1.8$ & $30.9 \pm 2.4$ \\
\hline
\end{tabular}

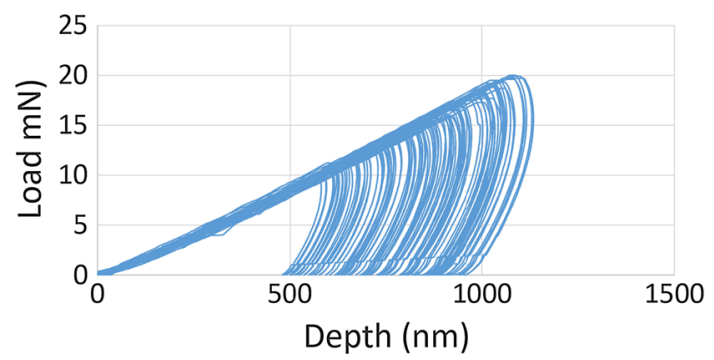

Fig. 3 Hundred Indentation tests on irradiated and non-irradiated areas. Loading from 10 to $20 \mathrm{mN}$

well below the total implanted layer thickness, with the indentation depth in the range 100-250 $\mathrm{nm}$.

\subsection{Optical, Atomic Force and Ultrasonic Microscopies}

The indentation network [01,01-10,10] was observed by optical microscopy (OM), atomic force microscopy (AFM) and ultrasonic force microscopy (UFM), as shown in Fig. 5.

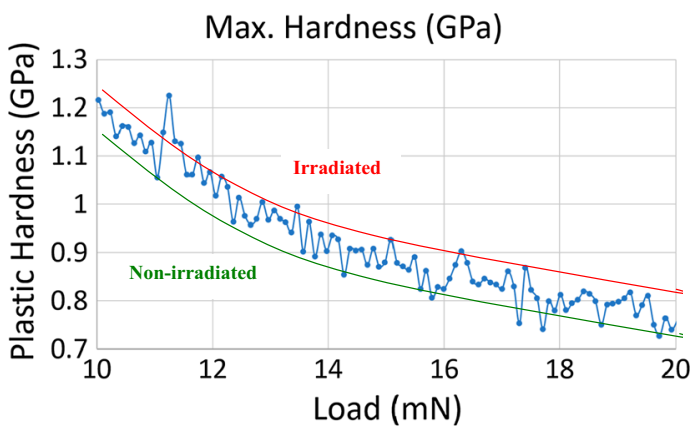

Fig. 4 Pre-analysis of indentation tests maximum hardness-load plot revealing the irradiated (higher) and non-irradiated (lower) values

The OM images (Fig. 5a and b) show that the lower loading indents $([01,01]$ and after) are to be found at the right side of the image, opposite to the larger loading indents (i.e., $[10,10])$ on the left side. The microscopic pictures of Fig. 5(a) and (b) 


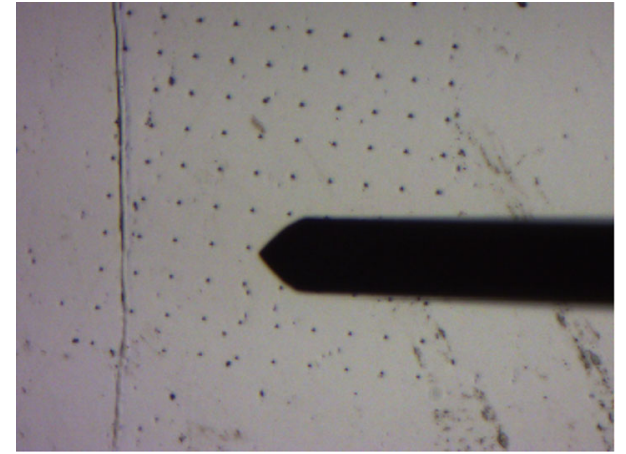

(a) In-situ OM imaging

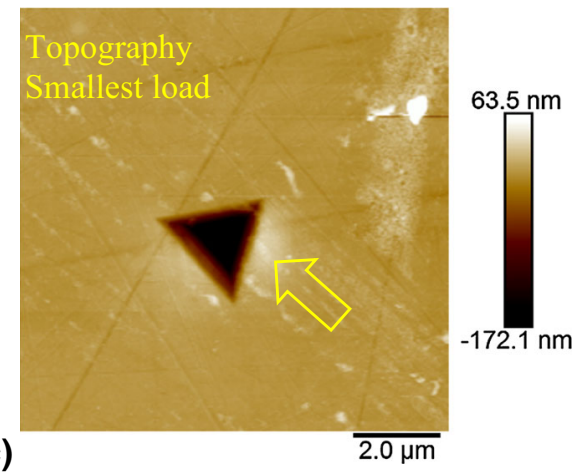

(c)

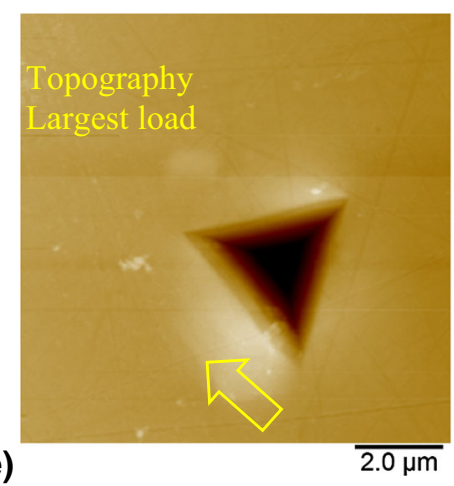

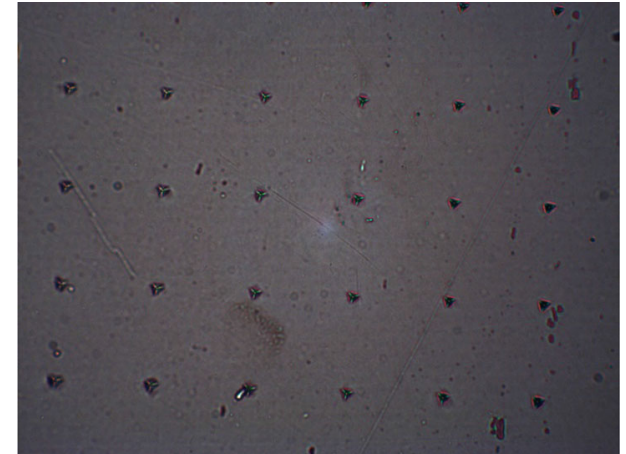

(b) 40x magnification

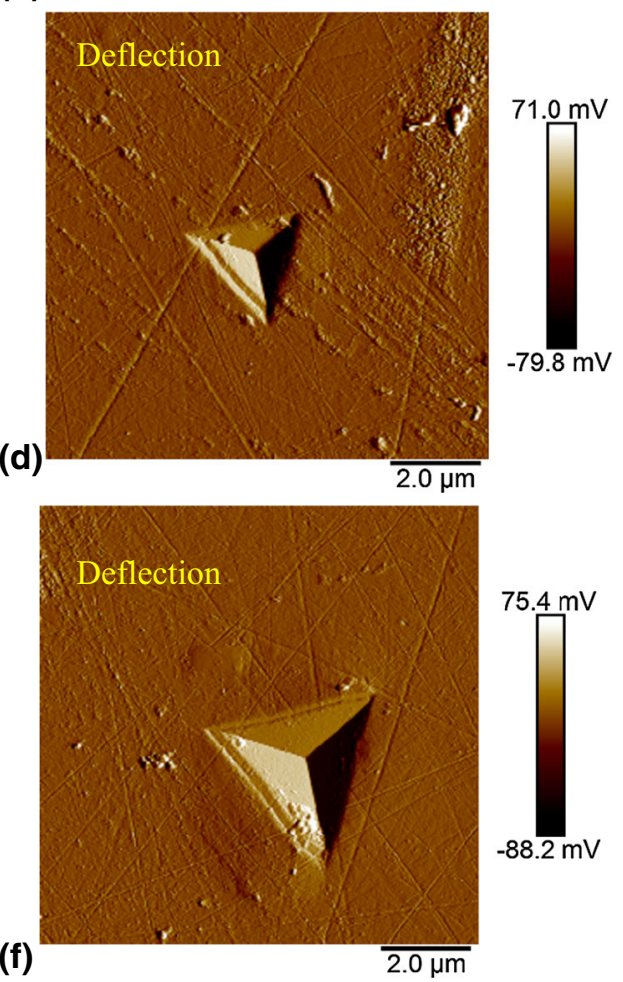

Fig. 5 Nanoindented sample as observed by OM (a, b), AFM (c, e) and UFM (d, f), for the lowest (c, d images) and largest (e, f images) load. Arrows showing the areas of residual plastic deformation

also show no significant increase in indent size that would be expected from swelling.

Images of the nanoindents for the lowest $(10 \mathrm{mN})$ and largest loads $(20 \mathrm{mN})$ are given in Fig. 5(c) and (e) (AFM) and Fig. 5(d) and (f) (UFM), respectively. For the AFM images in Fig. 5(c) and (e), grain displacements are suggested by arrows (said grain typically $10 \mu \mathrm{m}$ in size). Thus, these arrows also represent areas of residual plastic deformation. From the images in Fig. 5(c)-(f), indent sizes were found to be $2.45 \mu \mathrm{m}$ for $10 \mathrm{mN}$ and $3.85 \mu \mathrm{m}$ for $20 \mathrm{mN}$ corresponding to hardness's of 1.20 and $0.75 \mathrm{GPa}$, respectively, based on the hardness versus load curve in Fig. 4. The indent properties for the minimum and maximum load conditions are given in Table 3 .

From the AFM and UFM micrographs in Fig. 5(c)-(f), no indications of open or closed cracks are observed for loads up to $20 \mathrm{mN}$. The fact that no cracks are clearly visible suggests that the ductility of the material is greater than expected. The effect of implantation did not significantly reduce the ductility, and no significant swelling is observed in the implanted zones.
Table 3 Dimensions and characteristics of the indents determined by AFM and UFM, with hardness values taken from the nanoindentation results of Fig. 4

\begin{tabular}{lcccc}
\hline Coordinate & Load, mN & Size, nm & Depth, nm & Hardness, GPa \\
\hline 01.01 & 10 & 2450 & 299 & $1.20 \pm 0.15$ \\
10.10 & 20 & 3500 & 440 & $0.75 \pm 0.08$ \\
\hline
\end{tabular}

However, as described in the previous section, the plot of the hardness from the nanoindentations, shown in Fig. 4, suggests clear differences in hardness across the sample from one indentation to another. As the load difference between indentations is not large enough to observe these differences, the most likely explanation of the observed increase in hardness in Fig. 4 would therefore be the successful implantation of $\mathrm{He}^{2+}$ into the structure. 


\section{Discussion}

Over the last few decades, the study of the behavior of steel under irradiation has been a key topic. Authors such as Randall and Renevier (Ref 34), Hosemann et al. (Ref 19) and Lupinacci et al. (Ref 35) have shown that steel materials behave well during irradiation from the grain to the atomistic level. For example, Hosemann did not detect any pileup during nanoindentation measurements of ferritic/martensitic stainless steels grades. Furthermore, in the early studies of Madden and Callen (Ref 7) on the microstructure of neutron (thermal and fast) irradiated $20 \mathrm{Cr} / 25 \mathrm{Ni} / \mathrm{TiN}$ austenitic stainless steel, similar in composition to AGR clad, at $783 \mathrm{~K}$ showed that the steel was found to be relatively unaffected by irradiation at neutron fluence levels of $5.0 \times 10^{24} \mathrm{~m}^{-2}$ (thermal) and $2.5 \times 10^{24} \mathrm{~m}^{-2}$ (fast) and helium bubble embrittlement was unlikely under normal stresses. This has since been confirmed for various steel types in several other more recent studies, for example Fave et al. (Ref 36) who describe a similar response for ODS steels with lower He energy ions and shallower penetrations.

The nanoindentation results of section 3.3 show that nanoscopic damage with only a small hardness increase ( $\sim 10 \%)$ occurs with He irradiation. Additionally, no cracks or significant swelling are observed for the applied loads by either OM, AFM or UFM of indents.

This is in contrast to results by Lupinacci et al. (Ref 35) who have reported in a recent study that 304 stainless steel undergoes significant hardness increases after irradiations of 1 and $10 \mathrm{dpa}$, associated with plastic deformation in the irradiated area. However, this difference may be explained thus: first, damage calculations for the results reported here show that the irradiation damage levels are well below $1 \mathrm{dpa}$ in accordance with the observed hardness results, and secondly AGR steel has a significantly different composition to 304 and is stabilized akin to an ODS steel by the NbCN nanoinclusions.

Comparison of the results reported here may also be made with those presented in recent studies by Kim et al. (Ref 37) and Chen et al. (Ref 38). Kim et al. (Ref 37) investigated the microstructural evolution of NF709 (20Cr-25Ni-1.5MoNbTiN) under neutron irradiation. For $3 \mathrm{dpa}$, the hardness was observed to increase from about 3 (non-irradiated) to $5 \mathrm{GPa}$ (irradiated). In this work, the damage is smaller and the variation of hardness is consequently smaller. Chen et al. looked at the effect of grain orientation on nanoindentation behavior of a model austenitic alloy $\mathrm{Fe}-20 \mathrm{Cr}-25 \mathrm{Ni}$ (similar composition to AGR clad). They found that there is only a small effect of $\sim 10 \%$ hardness difference by stressing along different grain orientations for a depth $>1 \mathrm{~nm}$. This is similar to that observed here for grain displacements induced by He implantation.

In summary, the implantation of $\mathrm{He}^{2+}$ using an accelerator has been successfully achieved, mimicking the He concentration and energy encountered in AGR cladding after irradiation during current operation. Nanoindentation has been used to assess the effect of He irradiation on the mechanical properties of the AGR cladding steel. As described above, there are no observed fundamental differences between implanted and nonimplanted areas of the AGR steel confirming the work of Madden and Callen (Ref 7).

Further development of the present preliminary study will initially involve a detailed investigation of the influence of helium on the mechanical properties of the implanted steel in the He doped shallow layers. A low angle slope cut extending across the $10 \mu \mathrm{m}$ implanted depth over approximately $100 \mu \mathrm{m}$ shall be studied in using metallographic microscopes and scanning probe microscopes to explore in detail the mechanical properties along the $\mathrm{He}$ implanted depth and transitions between implanted and original layers.

\section{Conclusions}

The production of a non-active sample simulating He gas bubble formation in AGR cladding material during reactor operation has been successfully achieved. Such an approach is important because after in-reactor operation or alternatively after neutron irradiation AGR cladding is highly radioactive and can only be analyzed in hot cells. The approach used here has been instead to implant $\mathrm{He}^{2+}$ using an accelerator and perform sequential implantation with decreasing energy to mimic the buildup of $\mathrm{He}$ (e.g., $50 \mathrm{appm}$ ) in the irradiated cladding material in layers of the order of $10 \mu \mathrm{m}$. The implanted sample was subsequently analyzed by SEM, nanoindentation, atom force and ultrasonic force microscopies. As expected the irradiated zones undergo nanoscopic damages with only a small hardness increase $(\sim 10 \%)$. Cracks were not observed for any of the applied loads. Thus, for the tested AGR clad, there are no observed fundamental mechanical differences between implanted and non-implanted areas of the AGR steel confirming the integrity of the steel cladding under the applied He fluence conditions.

\section{Open Access}

This article is distributed under the terms of the Creative Commons Attribution 4.0 International License (http://creativecom mons.org/licenses/by/4.0/), which permits unrestricted use, distri bution, and reproduction in any medium, provided you give appropriate credit to the original author(s) and the source, provide a link to the Creative Commons license, and indicate if changes were made.

\section{References}

1. B.J. Marsden and G.N. Hall, Graphite in Gas-Cooled Reactors, Reference Module in Materials Science and Materials Engineering, Current as of 28 October 2015 (2016)

2. L.R. Greenwood, D.W. Kneff, R.P. Skowronski, and F.M. Mann, A Comparison of Measured and Calculated Helium Production in Nickel Using Newly Evaluated Neutron Cross Sections for ${ }^{59} \mathrm{Ni}, J$. Nucl. Mater., 1984, 123, p 1002-1010

3. V. Gopalakrishnan, R.V. Nandedkar, and S. Ganesan, Comparison of Calculated Helium Production in Stainless Steel Due to Neutron Irradiation with Experiment, J. Nucl. Mater., 1996, 228, p 207-214

4. I.J. Ford, Intergranular Fracture of Fast Reactor Irradiated Stainless Steel, Acta Metall. Mater., 1992, 40, p 113-122

5. S.L. Mannan and P.V. Sivaprasad, Austenitic Stainless Steels for InCore Applications of Fast Breeder Reactors, Reference Module in Materials Science and Materials Engineering, Current as of 22 July 2016 (2016)

6. G.R. Odette and G.E. Lucas, Embrittlement of Nuclear Reactor Pressure Vessels, J. Nucl. Mater., 2001, 53, p 18-22

7. P.K. Madden and V.M. Callen, The Microstructure of Neutron Irradiated $20 \mathrm{Cr} / 25 \mathrm{Ni} / \mathrm{TiN}$ Austenitic Stainless Steel, J. Nucl. Mater. 1983, 113, p 46-57 
8. G.R. Odette and G.E. Lucas, The Effects of Intermediate Temperature Irradiation on the Mechanical Behavior of 300-Series Austenitic Stainless Steels, J. Nucl. Mater., 1991, 179-181, p 572-576

9. N. Hashimoto, R.L. Klueh, and K. Shiba, Pros and Cons of Nickel and Boron-Doping to Study Helium Effects in Ferritic/Martensitic Steels, J. Nucl. Mater, 2002, 307-311, p 222-228

10. R.L. Klueh, N. Hashimoto, M.A. Sokolov, P.J. Maziasz, and S. Jitsukawa, Mechanical Properties of Neutron-Irradiated Nickel-Containing Martensitic Steels: II. Review and Analysis of Helium-Effects Studies, J. Nucl. Mater., 2006, 357, p 169-182

11. T. Yamamoto, G.R. Odette, H. Kishimoto, J.-W. Rensman, and P. Miao, On the Effects of Irradiation and Helium on the Yield Stress Changes and Hardening and Non-hardening Embrittlement of $\sim 8 \mathrm{Cr}$ Tempered Martensitic Steels: Compilation and Analysis of Existing Data, J. Nucl. Mater, 2006, 356, p 27-49

12. M.A. Pouchon, A.J. Kropf, A. Froideval, C. Degueldre, and W. Hoffelner, An X-Ray Absorption Spectroscopy Study of an oxide Dispersion Strengthened Steel, j. Nucl. Mater., 2007, 362, p 253-258

13. S. Cammelli, C. Degueldre, G. Kuri, and J. Bertsch, Study of a Neutron Irradiated Reactor Pressure Vessel Steel by X-Ray Absorption Spectroscopy, Nucl. Instrum. Methods B, 2008, 266, p 4775-4781

14. C. Degueldre, G. Kuri, M. Martin, A. Froideval, S. Cammelli, A. Orlov, J. Bertsch, and M.A. Pouchon, Nuclear Material Investigations by Advanced Analytical Techniques, Nucl. Instrum. Methods B, 2010, 268, p 3364-3370

15. Y. Dai, J. Henry, Z. Tong, X. Averty, and B. Long, Neutron/proton Irradiation and $\mathrm{He}$ Effects on the Microstructure and Mechanical Properties of Ferritic/Martensitic Steels T91 and EM10, J. Nucl. Mater. 2011, 415, p 306-310

16. I. Villacampa, J.C. Chen, P. Spätig, H.P. Seifert, and F. Duval, Helium Bubble Evolution and Hardening in $316 \mathrm{~L}$ by Post-Implantation Annealing, J. Nucl. Mater, 2018, 500, p 389-402

17. S. Jublot-Leclerc, M.-L. Lescoat, F. Fortuna, L. Legras, X. Li, and A. Gentils, TEM Study of the Nucleation of Bubbles Induced by $\mathrm{He}$ Implantation in $316 \mathrm{~L}$ Industrial Austenitic Stainless Steel, J. Nucl. Mater., 2015, 466, p 646-652

18. W.B. Liu, Y.Z. Ji, P.K. Tan, C. Zhang, C.H. He, and Z.G. Yang, Microstructure Evolution During Helium Irradiation and Post-irradiation Annealing in a Nanostructured Reduced Activation Steel, J. Nucl. Mater., 2016, 479, p 323-330

19. P. Hosemann, C. Vieh, R.R. Greco, S. Kabra, J.A. Valdez, M.J. Cappiello, and S.A. Maloy, Nanoindentation on Ion Irradiated Steels, J. Nucl. Mater., 2009, 389, p 239-247

20. P.P. Liu, F.R. Wan, and Q. Zhan, A Model to Evaluate the Nanoindentation Hardness of Ion-Irradiated Materials, Nucl. Instrum. Methods B, 2015, 342, p 13-18

21. Z.N. Ding, C.H. Zhang, Y.T. Yang, Y. Song, A. Kimura, and J. Jang, Hardening of ODS Ferritic Steel Under Irradiation with High-Energy Heavy Ions, J. Nucl. Mater., 2017, 493, p 53-61

22. A.L. Marzoca, M.I. Luppo, and M. Zalazar, Identification of Precipitates in Weldelements Performed in an ASTM A335 Gr P91 Steel by the FCAW Process, Procedia Mater. Sci., 2015, 15, p 119-122
23. D. Newey, M.A. Wilkins, and H.M. Pollock, An Ultra-Low Load Penetration Hardness Tester, J. Phys. E Sci. Instrum., 1982, 15, p 119122

24. E.S. Berkovich, Three-Faceted Diamond Pyramid for Studying Microhardness by Indentation, Zavodskaya Laboratoria, 1950, 13, p 345-347 ((in Russian))

25. N.A. Sakharova, J.V. Fernandes, J.M. Antunes, and M.C. Oliveira, Comparison Between Berkovich, Vickers and Conical Indentation Tests: A Three-Dimensional Numerical Simulation Study, Int. J. Solids Struct., 2009, 46, p 1095-1104

26. W.C. Oliver and G.M. Pharr, An Improved Technique for Determining Hardness and Elastic-Modulus Using Load and Displacement Sensing Indentation Experiments, J. Mater. Res., 1992, 7, p 15641583

27. J.L. Bosse, P.D. Tovee, B.D. Huey, and O.V. Kolosov, Physical Mechanisms of Megahertz Vibrations and Nonlinear Detection in Ultrasonic Force and Related Microscopies, J. Appl. Phys., 2014, 115, p 144304

28. A. Briggs and O.V. Kolosov, Acoustic Microscopy, 2nd ed., Oxford University Press, Oxford, 2009

29. R. Gr. Maev, Acoustic Microscopy: Fundamentals and Applications, Wiley, New York, 2008

30. F. Dinelli, S.K. Biswas, G.A.D. Briggs, and O.V. Kolosov, Ultrasound Induced Lubricity in Microscopic Contact, Appl. Phys. Lett., 1997, 71, p 1177-1179

31. J.F. Ziegler, M.D. Ziegler, and J.P. Biersack, SRIM-The Stopping and Range of Ions in Matter, Nucl. Instrum. Methods B, 2010, 268, p 18181823

32. J.P. Biersack and L.G. Haggmark, A Monte Carlo Computer Program for the Transport of Energetic Ions in Amorphous Targets, Nucl. Instrum. Methods, 1980, 174, p 257-269

33. J.F. Ziegler, J.P. Biersack, and U. Littmark, The Stopping and Range of Ions in Matter, Pergamon, New York, 1985

34. N.X. Randall, N. Renevier, H. Michel, and P. Collignon, Correlation Between Processing Parameters and Technical Properties as a Function of Substrate Polarization and Depth in a Nitrided 316L Stainless Steel Using Nanoidentation and Scanning Force Microscopy, Vaccum, 1997, 48, p 849-855

35. A. Lupinacci, K. Chen, Y. Li, M. Kunz, Z. Jiao, G.S. Was, M.D. Abed, A.M. Minor, and P. Hosemann, Characterisation of Ion Beam Irradiated 304 Stainless Steel Utilising Nanoidentation and Laue Microdiffraction, J. Nucl. Mater., 2015, 458, p 70-76

36. L. Fave, M.A. Pouchon, M. Döbeli, M. Schulte-Borchers, and A. Kimura, Helium Ion Irradiation Induced Swelling and Hardening in Commercial and Experimental ODS Steels, J. Nucl. Mater., 2014, 445, p 235-240

37. B.K. Kim, L. Tan, Y. Yang, X. Zhang, and M. Li, Micro Structural Evolution of NF709 (20Cr-25Ni-1.5MoNbTiN) Under Neutron Irradiation, J. Nucl. Mater., 2015, 470, p 229-235

38. T. Chen, L. Tan, Z. Lu, and H. Xu, The Effect of Grain Orientation on Nanoindentation Behavior of Model Austenitic Alloy Fe-20Cr-25Ni, Acta Mater., 2017, 138, p 83-91 